\title{
Stimulus functions within a fixed-interval clock schedule: Reinforcement, punishment, and discriminative stimulus control
}

\author{
R. J. AUGE \\ Denison University, Granville, Ohio 43023
}

\begin{abstract}
Pigeons received food for responding on a fixed-interval 32-sec schedule divided into three equal parts, each correlated with a distinctive, response-independent, visual stimulus. Response rate was very low during the first two thirds of the interval but high during the terminal third. When a response-dependent brief stimulus correlated with the terminal third was arranged for each response in the presence of the stimuli correlated with the first two thirds, response rate was enhanced, especially in the middle third. However, response rate was suppressed when each response in the presence of the stimulus correlated with the final third produced a brief stimulus correlated with the initial third. A similar suppressive effect occurred when each response produced a brief stimulus correlated with the middle third. Response suppression decreased over successive responsedependent brief-initial-stimulus manipulations. The results were interpreted in terms of reinforcement, punishment, and discriminative stimulus control by visual stimuli correlated with parts of a fixed-interval schedule.
\end{abstract}

Control of fixed-interval (FI) behavior by exteroceptive, discriminative stimuli can be demonstrated with either a continuous or discontinuous visual clock which demarcates the passage of time during an interval. For example, in experiments by Ferster and Skinner (1957), a small slit of light grew continuously and linearly throughout a 10-min interval, reaching its maximum size at reinforcement. Following reinforcement, the clock reset to an initial value and started recycling. Ferster and Skinner showed that the pause after reinforcement lengthened and the terminal response rate increased as control by the clock developed.

More recent studies of FI clock schedules (Farmer \& Schoenfeld, 1966; Hendry \& Dillow, 1966; Hendry, Yarczower \& Switalski, 1969; Kendall, 1972; Laties $\&$ Weiss, 1966; Segal, 1962) have used a discontinuous clock where, for instance, an FI schedule might be divided into four equal parts by four successive, distinctive, visual stimuli reliably correlated with the passage of time. The stimuli may either be responseindependent or response-dependent. Segal (1962) showed that compared to an FI schedule signaled by a single stimulus, an FI with a response-independent clock suppressed responding in the first three

This research was supported by a Faculty Development stipend from Denison University. Preparation of the manuscript was supported, in part, by a grant from the Denison University Research Foundation. I thank Joel Myerson for his helpful comments on an earlier version of the manuscript. Some of these data formed the basis for a paper given at the meeting of the Midwestern Association of Behavior Analysis, Chicago, May 1976. Reprints may be obtained from the author, Department of Psychology, Denison University, Granville, Ohio 43023 . quarters of the interval. Moreover, when brief clock stimuli were response-dependent, the data suggested that the early stimuli functioned as $\mathrm{S}-\mathrm{s}$ and conditioned punishers, perhaps because of their temporal distance from food, whereas the later stimuli (especially the terminal clock stimulus) functioned as $\mathrm{S}+\mathrm{s}$ and conditioned reinforcers, presumably because of their temporal proximity to food. ${ }^{1}$

A systematic replication of Segal's experiment by Kendall (1972) showed that the control exerted by the brief stimuli of a response-dependent FI clock schedule is particularly evident when one compares response rates under successive portions of a clock condition with response rates during corresponding portions of a single stimulus condition. Kendall trained pigeons to respond on an FI schedule where each peck on the key produced either the same brief visual stimulus (single stimulus condition) or a different brief visual stimulus (clock condition) during successive sixths of the FI schedule. Generally, response rates were much lower during the clock condition than during the single stimulus condition. This was especially true during Segments 2 through 5 (see Kendall, 1972, Experiment 1). Furthermore, as in the Ferster and Skinner studies, the pause following reinforcement was longer in the clock condition than in the single stimulus condition. It seems that the responsedependent presentation of brief visual stimuli correlated with the early portions of the FI schedule punished further responding and lengthened the pause following reinforcement (cf. Schneider, 1969).

In an experiment (Kendall, 1972, Experiment 2) using a two-key optional clock procedure (Hendry \& Dillow, 1966), responding on the "clock key" 
briefly produced one of three stimuli correlated with the three successive minutes of an FI schedule. The first response on a second key following the end of the interval produced food. Kendall found that availability of the stimulus correlated with the third and final minute of the FI schedule was the only stimulus necessary to maintain pecking on the clock key. In other words, only the stimulus correlated with the terminal segment functioned as a conditioned reinforcer, presumably because of its relative proximity to food. Kendall's data also argue against a suggestion by Hendry and Dillow (1966), who speculated that all of the stimuli in an FI clock schedule become reinforcing, not just the stimulus closest to reinforcement.

Although both Kendall (1972) and Segal (1962) have suggested that response-dependent brief stimuli correlated with the early portions of an FI clock schedule are punishing (cf. Dews, 1970), direct evidence of suppression relative to baseline responding is unavailable. If such stimuli were aversive, their response-dependent brief presentation might punish responding during the terminal segment of a response-independent FI clock schedule. Additionally, if the stimulus correlated with the terminal segment of such a schedule can function as a conditioned reinforcer (cf. Kendall, 1972, Experiment 2), the response-dependent brief presentation of that stimulus might elevate responding during the postreinforcement period when response rate is relatively low. The following experiment tested these two suggestions using a response-independent FI clock baseline and superimposed response-dependent briefstimulus procedures.

\section{METHOD}

\section{Subjects}

Two adult, male White Carneaux pigeons were maintained between $75 \%$ and $80 \%$ of their free-feeding weights. P409 had a history of responding on multiple schedules using FI 4-sec and FI 11-sec components; P1991 was experimentally naive. The birds had continuous access to water and grit in their individual home cages.

\section{Apparatus}

Two sets of apparatus were used. A Grason-Stadler three-key pigeon chamber (Model 1122) with multiple stimulus projector assemblies was housed in a sound-attenuating chamber. The second chamber was a Lehigh Valley Electronics (Model 1519d) three-key pigeon chamber housed in a sound-attenuating room adjacent to the room containing the conventional relay switching and timing circuitry. A minimum force of approximately $15 \mathrm{~g}$ $(0.15 \mathrm{~N})$ was required to operate the center key of each chamber. White noise and the sound of a ventilation fan served to mask extraneous sounds. Data were recorded on digital counters and running time meters.

\section{Procedure}

Pretraining. Following autoshaping (Brown \& Jenkins, 1968), P1991 was given one session of FI 15-sec schedule training followed by 23 sessions on an FI $32-\mathrm{sec}$ schedule signaled by transillumination (white) of the center key. The key light was not transilluminated during the $4.0-\mathrm{sec}$ reinforcement cycle. The houselight remained on for the duration of a session. Sessions consisted of 50 reinforcements and were normally conducted 6 days per week.

P409 was not given pretraining but was directly exposed to the subsequent procedure.

Three-stage response-independent clock baseline (B). An FI 32-sec schedule was divided into three equal parts by three distinctive, visual stimuli. The first third was signaled by a blue keylight (S3), the second third by a horizontal white bar on a black background (S2), and the final third by a red keylight (S1). Hence, the lower the number assigned to a stimulus, the closer the stimulus is to food reinforcement. The stimuli were presented independently of responding. The first peck following completion of the interval terminated the red keylight and initiated the reinforcement cycle. Immediately following reinforcement, the onset of the $\mathrm{S} 3$ stimulus signaled the beginning of the next interval.

Response-dependent brief presentation of S1, S2, or S3. In the S1 brief-stimulus condition, each response occurring in the presence of the S2 or S3 stimulus produced a brief flash (either 0.5 or $1.0 \mathrm{sec}$, see below) of S1. Responses in the presence of S1 prolonged the duration of that stimulus (for 0.5 or $1.0 \mathrm{sec}$ ) in the first two thirds of the interval, but had no consequence in the terminal third when S1 was always response-independent. Following completion of the interval, a single response produced reinforcement. Responding never prolonged the duration of the segments or the total interval. In the $\mathrm{S} 2$ brief-stimulus condition, each response occurring in the presence of S1 or S3 produced a brief flash of S2. Responses in the presence of S2 prolonged the duration of that stimulus during the first and third segments of the interval. The S3 brief-stimulus condition was similar to the preceding conditions, except that response-dependent flashes of S3 could occur only during the second and third segments of the interval. The response that produced reinforcement never produced a brief stimulus but always occurred in the presence of the S1 stimulus. The key was dark during the 4.0 -sec reinforcement cycle.

The sequence of experimental manipulations was arranged in a different order for each bird. (The sequence can be obtained by noting the session numbers given on the $x$-axes of Figures 1 and 2.) For part of the experiment, the baseline condition was in effect for 4 days, followed by 3 days of a manipulation, followed by 4 days of baseline, followed by 3 days of a manipulation, etc. For the remainder of the experiment, the number of sessions devoted to the baseline condition and the manipulation conditions were longer, with changes normally made when two of the three response rate measures (see Results) showed no systematic change for $S$ consecutive days. P409 received the fixednumber-of-sessions condition first and the variable-number-ofsessions condition second; the opposite was the case for P1991. The Lehigh Valley Electronics chamber was used for the variablesessions part of the experiment with P1991; the Grason-Stadler chamber was always used with P409 and for the fixed-sessions part with P1991. Before continuing the experiment in the Grason-Stadler chamber, P1991 was given nine sessions of pretraining on the response-independent clock procedure.

The duration of brief-stimulus presentation was $0.5 \mathrm{sec}$ throughout the experiment for P1991 and during the fixed sessions part for P409. In the variable-sessions part for P409, the brief-stimulus duration was $1.0 \mathrm{sec}$. The latter timer setting was not originally planned, but was continued when it was discovered after a few sessions.

The total number of responses in each segment, the postreinforcement pause (PRP), and the interreinforcement interval (IRI) durations were recorded.

\section{RESULTS}

Figures 1 and 2 show response rates per second during each of the three segments of the FI schedule 


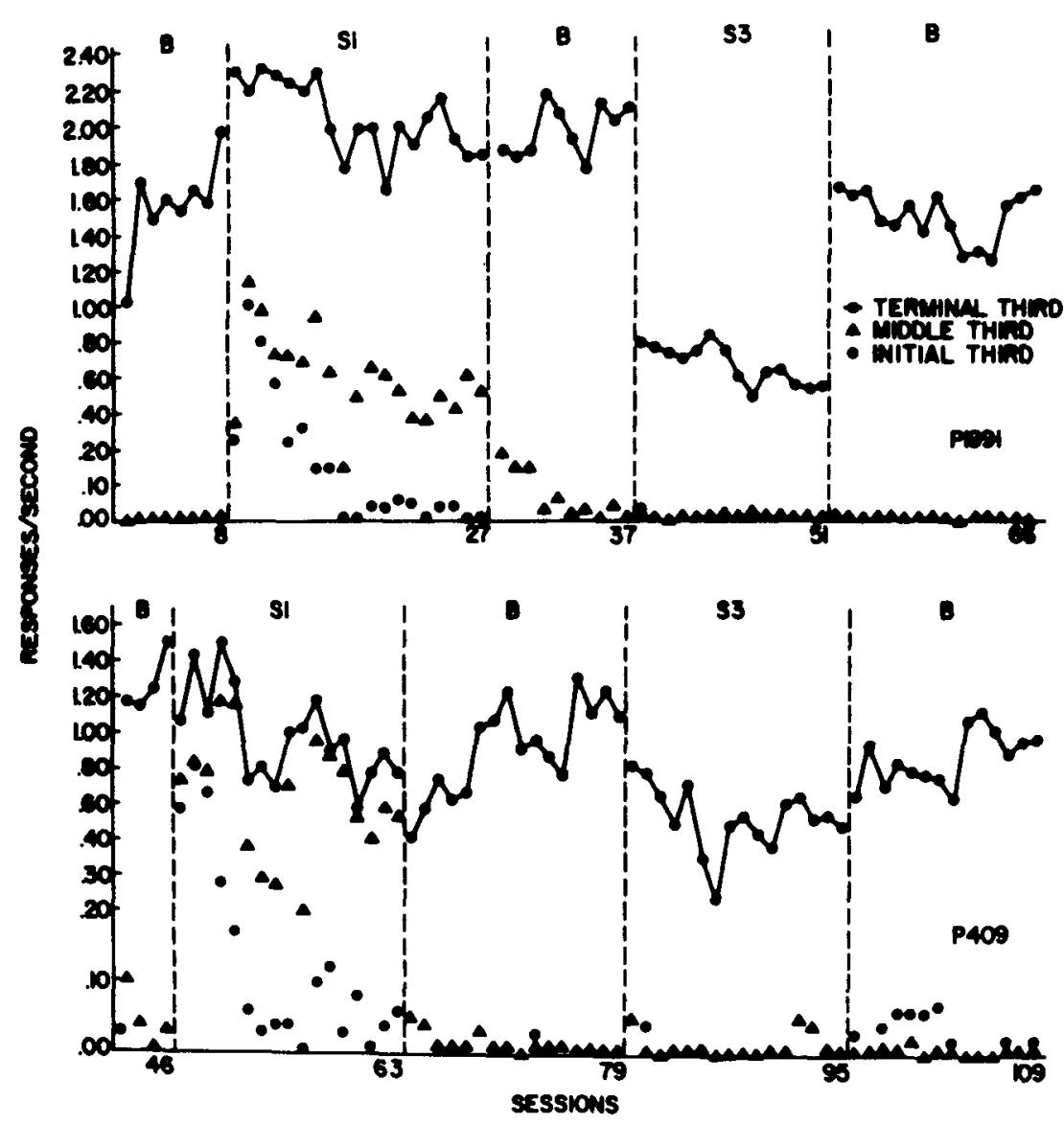

Figure 1. Response rates for the various conditions of the variable sessions part of the experiment. B represents the baseline condition; S1, the response-dependent flash of the stimulus correlated with the terminal third of the interval condition, etc. As in Figure 2, response rates less than 0.01 for the initial third of the interval are not plotted. Note the order of conditions as reflected by the session numbers of Figures 1 and 2.

for each session of the fixed-sessions and variablesessions parts of the experiment. Response rates were calculated by dividing the total number of responses in a particular segment by the total amount of time in that segment. In the case of the terminal segment, the total amount of time was slightly greater than the amount of time spent in either of the preceding two segments (see the IRI data below) since the response that produced reinforcement did not always occur at the instant the interval timed out. For the initial segment, only response rates of 0.01 or greater are plotted.

Typically, very little responding occurred during the first two segments of the interval in the responseindependent baseline clock condition. Continuous pausing during the $\mathrm{S3}$ stimulus was common for P1991 and occasionally occurred for P409. On the other hand, some responding always occurred during the S2 stimulus for both birds.

Response rates in the first two-thirds of the interval increased substantially when a brief flash of the S1 stimulus followed each response that occurred in the presence of the S3 or S2 response-independent stimuli. This increase in responding was typically greatest during the $\mathrm{S} 2$ stimulus, which signaled the middle third of the interval. Figure 1 shows that responding declined over sessions in the variablesessions part of the experiment for both birds but was relatively stable for the last five sessions of the S1 brief-stimulus condition. Following the manipulation, baseline performance was recovered.

Responding in the presence of the S1 stimulus was markedly suppressed when each response in its presence produced a brief flash of the S3 stimulus. For P1991, this suppression was immediate and pronounced, especially in the variable sessions part of the experiment. In the case of P409, response suppression clearly occurred (cf. the last five sessions with the last five sessions of the baseline phases in Figure 1) but was not as great as in the case of P1991.

When the response-independent baseline clock condition was reinstated, responding in the presence of the S1 stimulus increased for both pigeons. The increase approximated the former baseline for P409 but was somewhat less than the baseline preceding the manipulation for P1991. Responding during the 


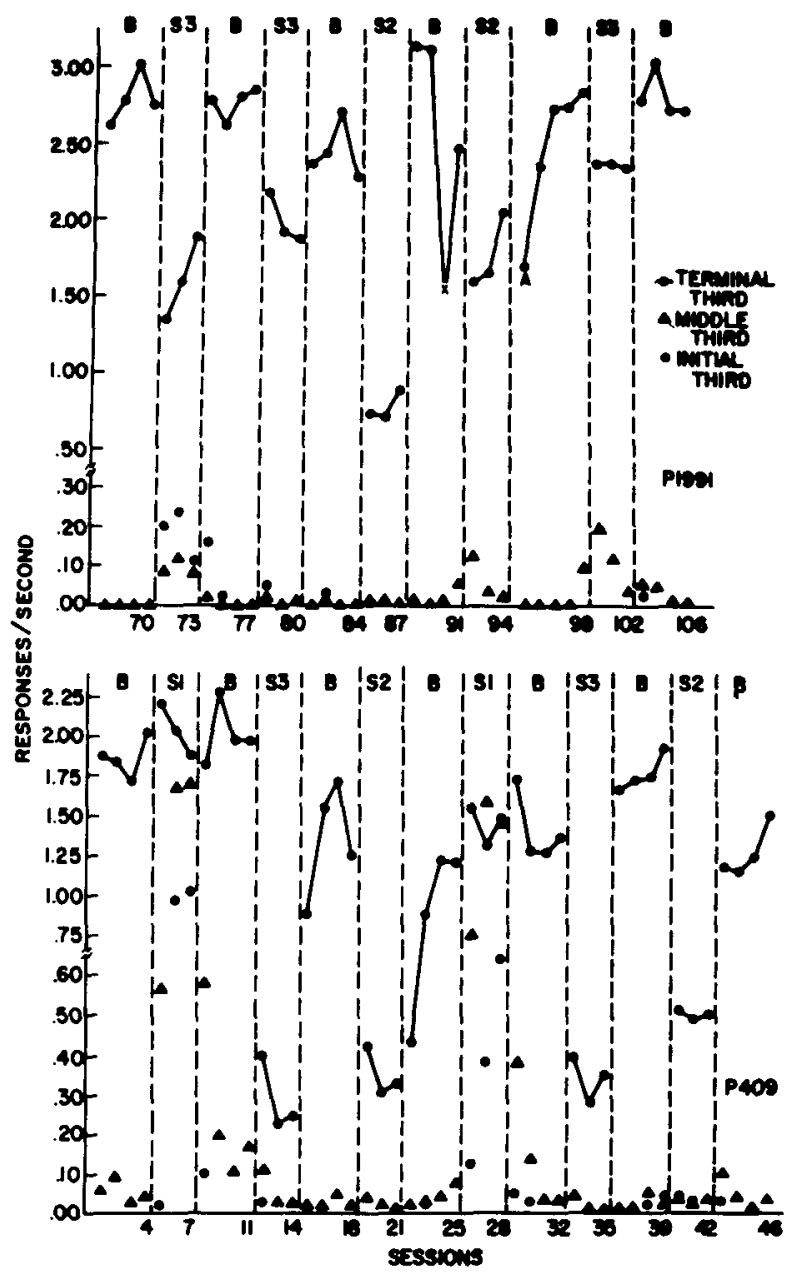

Figure 2. Response rates for the various conditions of the fixed sessions part of the experiment. For P1991, the session marked by $X$ was characterized by protracted pausing during one interval; the A marks apparatus failure.

S2 stimulus did not show much change between the baseline and brief flash of S3 conditions. However, note that the response rate in the presence of S3 was greater than that in the presence of S2 for nine sessions of the final baseline condition for P409 in the variable sessions (Figure 1) part of the experiment. Also, notice the elevation in response rate in the presence of S3 and S2 for P1991 in the fixed sessions (Figure 2) part of the experiment in the first brief flash of the $\mathrm{S} 3$ condition relative to the preceding and following baselines. For both birds, the S3 stimulus had a recent history of being closely associated with food, i.e., when it was responsedependent during the terminal third of the interval.

Figure 3 presents suppression ratios (SR) for successive S3 brief-flash manipulations for both birds. In computing the suppression ratio, the following formula was used:

$$
\mathrm{SR}=\frac{\mathrm{R}_{\mathrm{B}}}{\mathrm{R}_{\mathrm{B}}+\mathrm{R}_{\mathrm{S} 3}}
$$

where $\mathbf{R}_{\mathbf{B}}$ is the median response rate for the last three sessions of baseline, and $R_{S 3}$ is the median response rate for the first three sessions of the S3 brief-stimulus manipulation. Assuming that the response rate for the $\mathrm{S} 3$ condition does not increase relative to the baseline rate, the ratio varies from 0.5-no suppression-to 1.0-total suppression. Figure 3 shows that suppression decreased approximately linearly over successive S3 brief-stimulus manipulations.

Figure 4 shows response frequencies during baseline conditions and associated S3 or S2 brief-stimulus manipulations. Response frequency decreased markedly when either the S3 or the S2 stimulus was response-dependent in the terminal third of the interval.

Figure 5 gives median postreinforcement pauses (PRP) and interreinforcement intervals (IRI) in seconds for the last three sessions of fixed sessions and the last five sessions of variable sessions for the various conditions of the experiment. The PRP timer started operating with the offset of reinforcement and stopped operating when the first response in the interval occurred. Range bars for PRP are also presented. There was very little variability in the IRI within conditions, hence range bars are not presented for this measure. As a function of conditions, these measures showed more variability for P409 than for P1991. When a response-dependent flash of S1 was arranged, PRP was reduced for both pigeons relative to baseline conditions. Howver, when responding produced a brief flash of S3, PRP

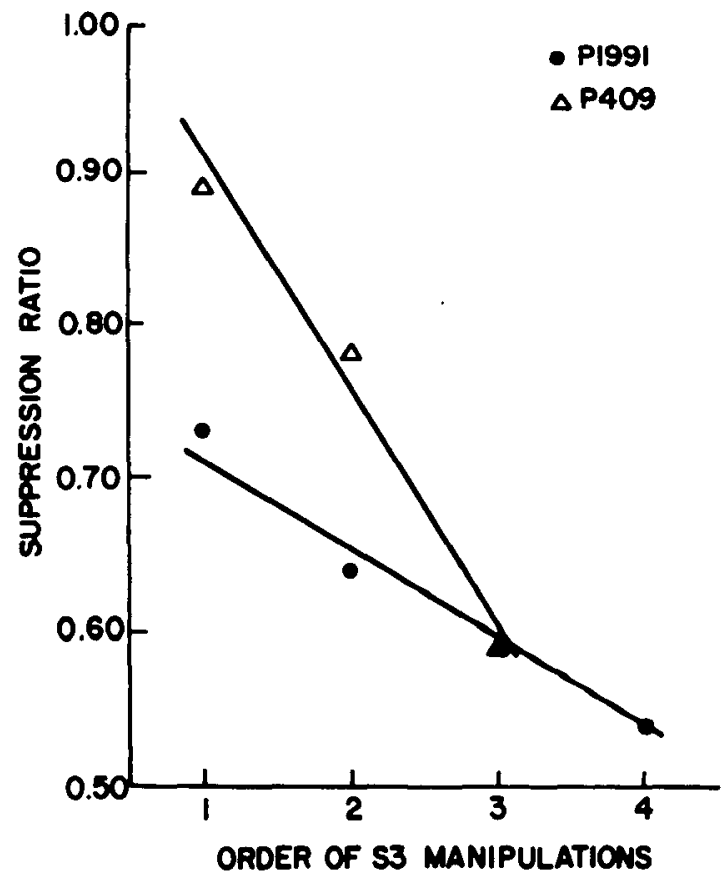

Figure 3. Response suppression ratio values plotted as a function of the order of response-dependent brief-initial-stimulus conditions. See text for details. 


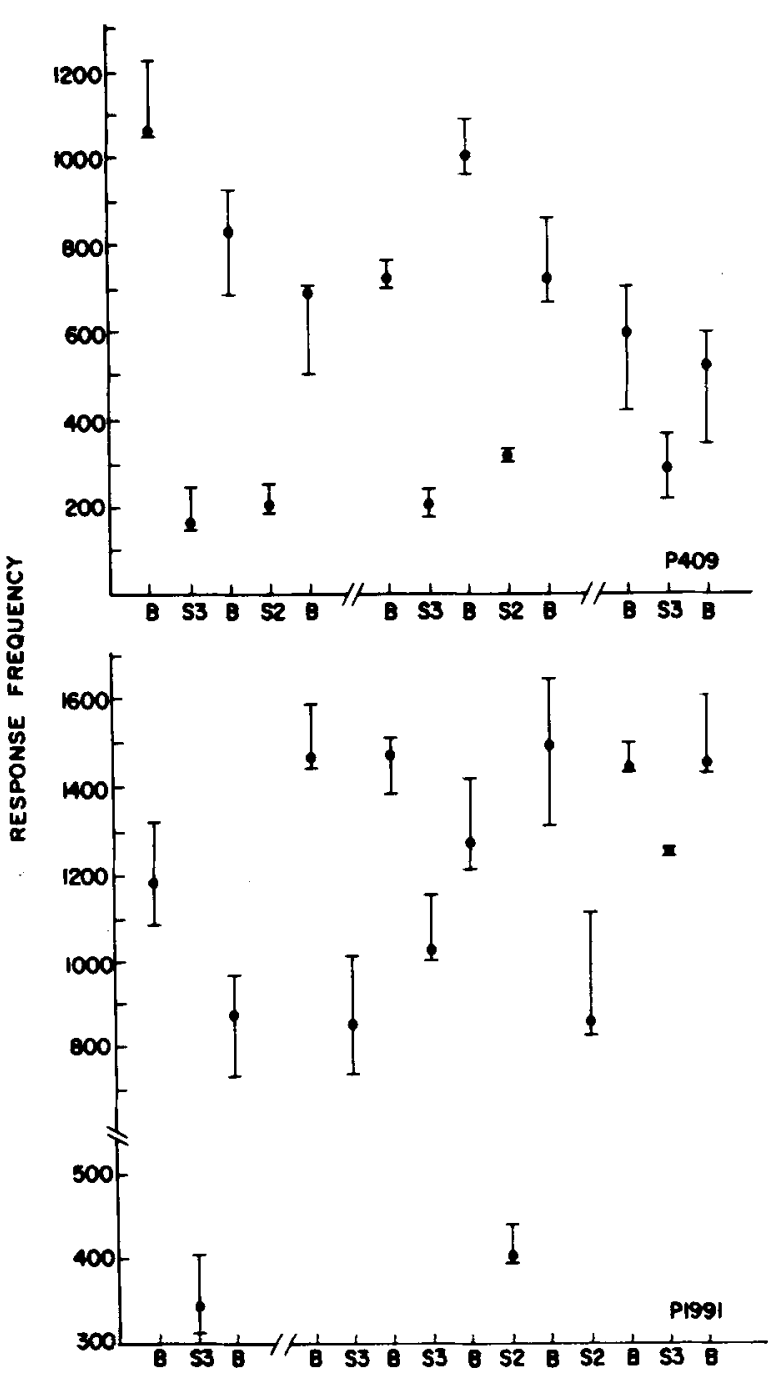

Figure 4. Median response frequencies for the last three sessions in fixed sessions or last seven sessions in variable sessions. Range bars are also included.

and IRI results were quite different for the two birds; for P409, both PRP and IRI tended to increase, whereas, for P1991, PRP either decreased or, like the IRI, showed little change. For both birds, when a brief response-dependent flash of S2 was arranged, changes in the PRP and IRI were small and inconsistent.

\section{DISCUSSION}

Two major effects were shown as a result of the present study. First, a response-dependent brief stimulus correlated with a relatively distant temporal interval from food-suppressed responding at a time when response rate was normally relatively high; both the stimulus correlated with the postreinforcement period and the stimulus correlated with the middle third of the FI had suppressive effects on response rate when one or the other was responsedependent in the terminal third of the interval.
Second, a response-dependent brief stimulus correlated with the terminal third of the interval shortened the PRP and increased responding in the first twothirds of the interval, when response rate was normally relatively low. This increase in response rate was greater in the middle third than in the initial third and, in the latter case, tended to decline over sessions. Throughout, response rate was high in the presence of the terminal stimulus in the responseindependent baseline clock condition; the PRP was relatively long, and comparatively few responses occurred in the first two-thirds of the interval, even though conditions were especially favorable for the development of superstitious responding in the middle third. This study showed that response frequency and rate can be substantially reduced by the response-dependent presentation of negative discriminative stimuli.

Reinforcement or punishment by a responsedependent brief stimulus correlated with a particular segment of the FI schedule might be considered the primary effect of a specific manipulation. A secondary effect, however, would be the positive or negative discriminative control exerted by a stimulus once it was produced (cf. Segal, 1962). If the stimulus were $\mathrm{S} 1$, a relatively high response rate would occur. However, if the stimulus were S3 or $\mathrm{S} 2$, a relatively low response rate or pausing would be induced. Responses that occurred during a brief stimulus prolonged the duration of that stimulus; during such time, a considerable amount of keypecking or pausing was probably under discriminative stimulus control. Yet the discriminative control could not occur until a response produced the controlling stimulus; for this reason, the stimulus control exerted by a response-dependent brief stimulus may be viewed as secondary to the reinforcing or punishing effect that resulted from the presentation of that stimulus. By recording responses during brief stimuli, and during the particular response-independent stimulus segment when the brief stimuli are available, it would be possible to separate discriminative stimulus control from control by reinforcement or punishment.

Suppression by response-dependent flashes of S3 decreased over successive manipulations, as shown in Figure 3. This decrease in suppression might be taken as evidence of learning to discriminate the response-independent presentation of S3 in the initial third from the response-dependent flash of S3 in the terminal third of the interval. Alternatively, with protracted exposure to the S3 brief-stimulus condition, or frequent shifts between that condition and the baseline condition, the S3 stimulus might cease to be punishing and become a conditioned reinforcer (and, perhaps, a positive discriminative stimulus because of its proximity to food when responsedependent in the terminal third of the interval). 


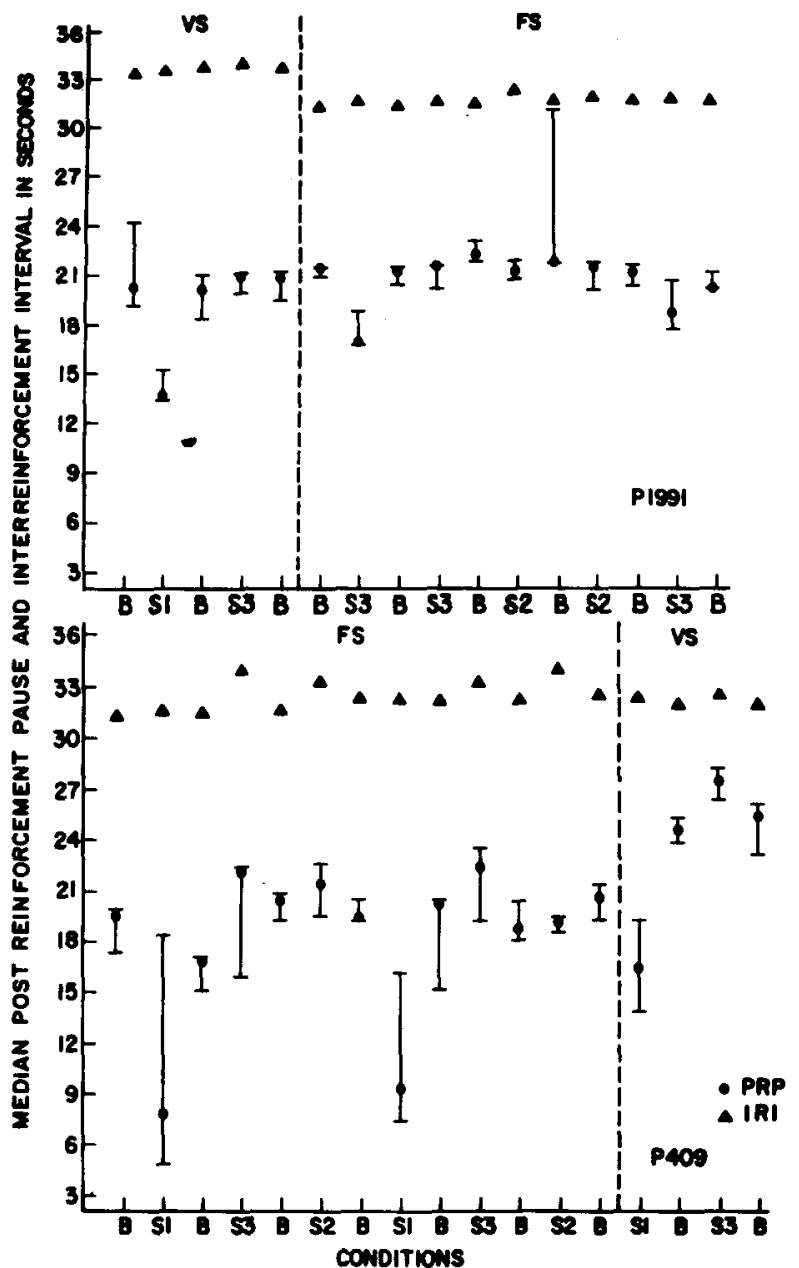

Figure 5. Median PRPs and IRIs for the various conditions of the experiment. Range bars for PRPs are also presented.

This experiment demonstrates the punishing effects of stimuli correlated with the early portions of an FI clock schedule, as suggested by Kendall (1972), and Segal (1962) and replicates Ferster and Skinner (1957) and Segal's (1962) findings regarding response-independent clock schedules. The present data strongly argue against the interpretation of Hendry and Dillow (1966), who suggested that all of the stimuli in an FI clock schedule become reinforcing, as measured by the tendency to produce them, not just the stimulus closest to reinforcement. Moreover, the present data suggest that the subjects in Kendall's (1972, Experiment 2, Condition 2) experiment did not observe the stimuli correlated with the first two-thirds of an FI 3-min schedule because they were aversive compared to the stimulus signaling the terminal third of the interval (cf. Auge, 1974; Mulvaney, Dinsmoor, Jwaideh, \& Hughes, 1974). In the present experiment, it can be argued that the S1 stimulus functioned as a conditioned reinforcer because a brief response-dependent flash of $\mathrm{S} 1$ increased responding in the first two-thirds of the interval. This corroborates Kendall (1972), who showed that the stimulus correlated with the terminal minute of an FI 3-min schedule functioned as a conditioned reinforcer for observing behavior.

Data from other paradigms support the view that stimuli correlated with the early portions of a fixed IRI are aversive. In studies of choice using concurrent chains paradigms, Duncan and Fantino (1972) and Wallace (1973) showed that an IRI associated with a single stimulus is preferred over a temporally equivalent IRI associated with two or more successive, distinctive visual stimuli, i.e., a clock condition. The present study suggests that, by segmenting an IRI, these experimenters "added" an aversive stimulus to the particular alternative involved and thus caused a preference for the IRI associated with a single stimulus (cf. Schneider, 1972).

Wilkie (1974), using a line-tilt dimension, found inhibitory stimulus control gradients during the early part of an FI schedule when the preceding interval terminated with reinforcement and blackout, but not blackout alone. Wilkie's data and the present data suggest that reinforcement offset, a period of time following that event, and the correlated exteroceptive stimuli are aversive. Furthermore, Brown and Flory (1972) showed that pigeons will respond to terminate the stimulus associated with an FI schedule; termination behavior typically occurred shortly after reinforcement, when the foregoing analysis suggests aversive stimuli occur. In addition, Richards and Rilling (1972) have shown that a pigeon is likely to attack another pigeon during the postreinforcement period on an FI schedule. Various "interim activities" (Staddon \& Simmelhag, 1971), or adjunctive behaviors (Falk, 1972) on fixed IRI schedules, such as attack, escape, and general activity (Killeen, 1975), might be, at least in part, a function of aversive properties of the postreinforcement period. The aversiveness of that period might be enhanced by the addition of a visual clock to the fixed IRI.

\section{REFERENCES}

AugE, R. J. Context, observing behavior, and conditioned reinforcement. Journal of the Experimental Analysis of Behavior. 1974, 22, 525-533.

Brown, T. G., \& Flory, R. K. Schedule-induced escape from fixed-interval reinforcement. Journal of the Experimental Analysis of Behavior, 1972, 17, 395-403.

Brown, P. L., \& Jenkins, H. M. Auto-shaping of the pigeon's key peck. Journal of the Experimental Analysis of Behavior, 1968, 11, 1-8.

DEws, P. B. The theory of fixed-interval responding. In W. N. Schoenfeld (Ed.), The theory of reinforcement schedules. New York: Appleton-Century-Crofts, 1970.

Duncan, B., \& Fantino, E. The psychological distance to reward. Journal of the Experimental Analysis of Behavior, 1972, 18, 23-34.

FALK, J. L. The nature and determinants of adjunctive behavior. In R. M. Gilbert \& J. D. Keehn (Eds.), Schedule effects: Drugs, drinking, and aggression. Toronto: University of Toronto Press, 1972 . 
FARMer, J., \& Schoenfeld, W. N. Varying temporal placement of an added stimulus in a fixed-interval schedule. Journal of the Experimental Analysis of Behavior, 1966, 9. 369-375.

FERSTER, C. B., \& Skinner, B. F. Schedules of reinforcement. New York: Appleton-Century-Crofts, 1957.

HendRY, D. P., \& Dillow, P. V. Observing behavior during interval schedules. Journal of the Experimental Analysis of Behavior, 1966, 9, 337-349.

Hendry, D. P., Yarczower, M., \& Switalski, R. C. Periodic shock with added clock. Joumal of the Experimental Analysis of Behavior, 1969, 12, 159-166.

Kendall, S. B. Some effects of response-dependent clock stimuli in a fixed-interval schedule. Joumal of the Experimental Analysis of Behavior, 1972, 17, 161-168.

Killeen, P. On the temporal control of behavior. Psychological Review, 1975, 82, 89-115.

LATIES, V. G., \& WEIss, B. Influence of drugs on behavior controlled by internal and external stimuli. Journal of Pharmacology and Experimental Therapeutics, 1966, 152, 388-396.

Mulvaney, D. E., Dinsmoor, J. A., Jwaideh, A. R., \& Hughes, L. H. Punishment of observing by the negative discriminative stimulus. Journal of the Experimental Analysis of Behavior. 1974, 21, 37-44.

RichaRds, R. W., \& Rilling, M. Aversive aspects of a fixedinterval schedule of food reinforcement. Journal of the Experimental Analysis of Behavior, 1972, 17, 405-411.

SCHNEIDER, B. A. A two-state analysis of fixed-interval responding in the pigeon. Journal of the Experimental Analysis of Behavior. 1969, 12, 677-687.

Schneider, J. W. Choice between two-component chained and tandem schedules. Journal of the Experimental Analysis of Behavior, 1972, 18, 45-60.

SEGAL, E. F. Exteroceptive control of fixed-interval responding. Journal of the Experimental Analysis of Behavior, 1962, 5, 49-57.
Staddon, J. E. R., \& Simmelhag, V. L. The "superstition" experiment: A re-examination of its implications for the principles of adaptive behavior. Psychological Review, 1971, 78, 3-43.

Wallace, R. F. Conditioned reinforcement and choice. Unpublished doctoral dissertation, University of California, San Diego, 1973.

WILKIE, D. M. Stimulus control of responding during a fixedinterval reinforcement schedule. Joumal of the Experimental Analysis of Behavior, 1974, 21, 425-432.

\section{NOTE}

1. In a FI schedule with a discontinuous clock consisting of four equal parts, identified by four successive, distinctive, visual stimuli, the first three stimuli are $\mathrm{S}-\mathrm{s}$, or negative discriminative stimuli, i.e., there is a zero correlation between responding and the production of food; when those stimuli are present, very little, if any, responding occurs. On the other hand, the terminal clock stimulus is an $\mathrm{S}+$ or positive discriminative stimulus, i.e., there is a positive correlation between responding and the production of food; when present, such a stimulus occasions considerable responding. Of course, it is also conceivable that the stimulus that precedes the terminal clock stimulus might become an $\mathrm{S}+$ or positive discriminative stimulus, because of its association with the terminal clock stimulus, and function as a conditioned reinforcer for keypecking when response-dependent [e.g., see Segal's (1962) data for responsedependent stimulus conditions].

(Received for publication August 9, 1976; revision accepted November $1,1976$. 